\title{
High Pressure Supercritical Carbon Dioxide Adsorption in Coal: Adsorption Model and Thermodynamic Characteristics
}

Xu Tang ${ }^{\mathrm{a}^{*}}$, Nino Ripepi ${ }^{\mathrm{a}, \mathrm{b}}$

(a Department of Mining and Minerals Engineering \& b Virginia Center for Coal and Energy Research, Virginia Polytechnic Institute and State University, Blacksburg, Virginia, 24060, U.S)

*Corresponding author: Xu TANG

Tel: +1 540-998-7174

Fax: +1 540-231-4070

Email: xutang@vt.edu; xutangcbm@gmail.com

Address: Department of Mining and Minerals Engineering, Virginia Polytechnic Institute and State University, 100 Holden Hall, Blacksburg, Virginia, 24060, U.S.

\begin{abstract}
This work uses a dual-site Langmuir adsorption model to describe supercritical carbon dioxide $\left(\mathrm{scCO}_{2}\right)$ adsorption in coal up to $20 \mathrm{MPa}$ and $253 \mathrm{~K}$. The isosteric heat of adsorption for $\mathrm{scCO}_{2}$ in coal is calculated analytically by considering both the real gas behavior and the adsorbed phase, which are ignored in the classic Clausius-Clapeyron approximation. It was found that the proposed model can not only reasonably interpret observed test phenomena but also has the intrinsic ability to extrapolate adsorption isotherms under different temperatures beyond test data. The crossovers of the observed adsorption isotherms under different temperatures are caused by the changing volume of the adsorbed phase during the adsorption process. Both the temperature dependence and adsorption uptake dependence of isosteric heat of adsorption are revealed; the higher the temperature and the adsorption uptake, the lower the isosteric heat of adsorption. The ideal gas law overestimates the isosteric heat of adsorption for $\mathrm{scCO}_{2}$ in coal. The application of the dual-site Langmuir model allows for estimating the $\mathrm{CO}_{2}$ storage capacity of deep unminable coal seams, modeling $\mathrm{CO}_{2}$ transport behavior via differentiating the true ratio between bulk phase and adsorbed phase, and investigating the true thermodynamic characteristics of $\mathrm{CO}_{2}$ in coal under high pressures.
\end{abstract}

Key words: carbon dioxide, adsorption, coal, Langmuir, isosteric heat of adsorption

Page 1 of 19

(C) 2016. This manuscript version is made available under the Elsevier user license http://www.elsevier.com/open-access/userlicense/1.0/ 


\section{Introduction}

Because of global warming and climate change concerns, global efforts have been made to decrease the concentration of carbon dioxide in the atmosphere (Grubb et al., 1995; Stern, 2009; Morgan et al., 2014; Paris Protocol, 2015). Carbon dioxide capture, utilization and storage are considered crucial ways to meet the carbon dioxide emission reduction targets. Onshore geological sequestration of carbon dioxide typically involves capturing, transporting and injecting carbon dioxide into suitable underground formations for storage such as depleted oil and conventional gas reservoirs, unconventional natural gas reservoirs (unminable coal seams and shale formations), deep saline formations $r$, and basalt formations (Herzog et al., 2001; White et al., 2003; Metz et al., 2005; Benson et al., 2008; Orr, 2009; Figueroa et al., 2008). Among these geological formations, unminable coal seams are one of the promising options because of their potential for enhancing coalbed methane (ECBM) recovery while simultaneously sequestering carbon dioxide (White et al., 2005; Mazzotti et al., 2009; Busch et al., 2011; Godec et al., 2014). The enhanced natural gas will help to offset the cost of carbon dioxide sequestration. However, there are still some concerns about the long-term effect of sequestration of $\mathrm{CO}_{2}$ in coal seams and potential environmental consequences (White et al., 2005; Hedges et al., 2005). Carbon dioxide injection issues arise during the field injection process because of the permeability decrease induced by coal swelling (Reucroft, et al., 1987; Pan et al., 2007 \& 2010; Cui et al., 2007; Day et al., 2008). The existing phases of the injected carbon dioxide in the subsurface are crucial for the carbon dioxide storage capacity estimation. Therefore, field tests of ECBM with carbon sequestration were and are being conducted around the world, which are helpful to understand the potential benefits and practical issues (Steven et al., 1998; Yamasaki, 2003; Gunter et al., 2004; Sams et al., 2005; White et al., 2005; Van Bergen, et al., 2006; Wong et al., 2007; Ripepi, 2009; Connell et al., 2013; Gilliland et al., 2013; Wei et al., 2015).

It is well known that the affinity of carbon dioxide in coal is higher than methane, and the amount of carbon dioxide adsorbed in coal is always higher than methane at the same pressure. In order to evaluate the carbon dioxide storage potential of unminable coal seams, the first step is to evaluate the adsorption capacity of carbon dioxide in coal via isothermal sorption tests. However, because of the heterogenous properties of coal, $\mathrm{scCO}_{2}$ adsorption behavior in coal has not garnered research attention like it has for manmade materials. There are inconsistent test phenomena reported regarding $\mathrm{scCO}_{2}$ adsorption in coal. Some researchers show peculiar test phenomena for $\mathrm{scCO}_{2}$ in coal such as the bimodal Gibbs excess adsorption isotherms (Krooss et al., 2002; Toribio et al., 2004; Busch et al., 2007; Siemons et al., 2007; Busch et al., 2008). Other researchers exhibit smooth $\mathrm{CO}_{2}$ excess adsorption isotherms in coal when the pressure rises up to 20MPa (Sudibandriyo et al., 2003; Fitzgerald et al., 2005; Bae et al., 2006; Ottiger et al., 2006; Sakurovs et al., 2007; Day et al., 2008; Pini et al., 2010; Weniger et al., 2010; Song et al., 2015; Luo et al., 2015). Since the latter test phenomena can be reproduced and the former cannot, the peculiar test phenomenon is attributed to artificial test errors (Ottiger et al., 2006; Pini et al., 2010). Even though the smooth $\mathrm{CO}_{2}$ excess adsorption isotherms have been observed, an optimized model for modeling both the Gibbs excess and absolute adsorption uptake is still needed. Despite extensive research for $\mathrm{scCO}_{2}$ adsorption in manmade materials, a number of semi-empirical models have been adopted by revising the classic $D-A, D-R$, Langmuir and Toth equations to describe the sorption behavior of $\mathrm{scCO}_{2}$ in coal by fitting each isothermal adsorption curves independently (Sudibandriyo et al., 2003; Fitzgerald et al., 2005; Bae et al., 2006; Ottiger et al., 2006; Sakurovs et al., 2007; Day et al., 2008; Pini et al., 2010; Schell et al., 2012; Weniger et al., 2010; Song et al., 2015; Luo et 
al., 2015; Moreira et al., 2017). However, all these models are based on either the empirical density of adsorbed carbon dioxide (density of liquid carbon dioxide) in coal or the assumed constant volume of adsorbed carbon dioxide in coal. Even though good fitting results are obtained by each researcher, the physical meaning of the obtained parameters from these revised classical equations still needs to be confirmed. Furthermore, even though the coal swelling phenomena has been observed, few models include coal swelling to obtain absolute isotherms from Gibbs excess isotherms (Ozdemir et al., 2003; Romanov et al., 2006; Pini et al., 2010). Considering both the adsorption and penetration (absorption) $\mathrm{CO}_{2}$ in coal may explain the coal swelling effect during the sorption process. The penetration $\mathrm{CO}_{2}$ can not only compensate the elastic energy change associated with volume change but also can change the macromolecular structure of coal (Jakubov et al., 2002; Larsen, 2004; Pini et al., 2010). In addition, these models cannot be used to extrapolate isotherms beyond test temperatures. The prediction of adsorption isotherms under high pressure and high temperature geological conditions are critical for carbon dioxide storage capacity estimations in the deep subsurface. Therefore, to reasonably interpret the adsorption behavior of $\mathrm{scCO}_{2}$ in coal and predict adsorption isotherms under high temperature and high pressure in-situ conditions, a more concise and robust adsorption model is needed.

As a crucial evaluation index for the thermodynamic process in physical adsorption tests, the isosteric heat of adsorption for $\mathrm{scCO}_{2}$ in coal has rarely been considered by researchers. There are still several issues that exist regarding the calculation of this index for $\mathrm{scCO}_{2}$ adsorption in coal (Pan et al., 1998; Chakraborty et al., 2006; Stadie, 2012; Baran et al., 2013; Stadie et al., 2013 \& 2015). First, the absolute adsorption isotherms must be obtained from the observed adsorption isotherms in order to calculate the isosteric heat of adsorption, where a robust model is needed (Herbst et al., 2002; Bae et al., 2006). Under low pressure conditions, the observed adsorption isotherm approximates the absolute adsorption isotherm, and there is no need to obtain the absolute adsorption isotherm. However, when the Gibbs excess adsorption behavior becomes obvious under higher pressure conditions, a reliable adsorption model is necessary to obtain the absolute adsorption uptake from observed adsorption isotherms. Second, even though the absolute adsorption isotherms can be obtained, the classic ClausiusClapeyron approach is not appropriate because it cannot take the real gas behavior of $\mathrm{scCO}_{2}$ and the adsorbed gas phase into consideration (Pan et al., 1998; Chakraborty et al., 2006; Stadie et al., 2015). Figure 1 shows the deviation of $\mathrm{CO}_{2}$ behavior compared with ideal gas under different temperatures and pressures. The usage of the Clausius-Clapeyron approach therefore will hide the true behavior of the isosteric heat of adsorption because the Clausius-Clapeyron approach uses the ideal gas assumption and neglects the adsorbed gas phase volume (Chakraborty et al., 2006; Stadie et al., 2015). It has been found that both the gas behavior and the adsorbed gas phase volume can significantly influence the isosteric heat of adsorption (Chakraborty et al., 2006; Mertens, 2009; Stadie et al., 2015). Therefore, in order to obtain the true behavior of the isosteric heat of adsorption, the real gas behavior and the adsorbed gas phase volume must be reasonably considered. 


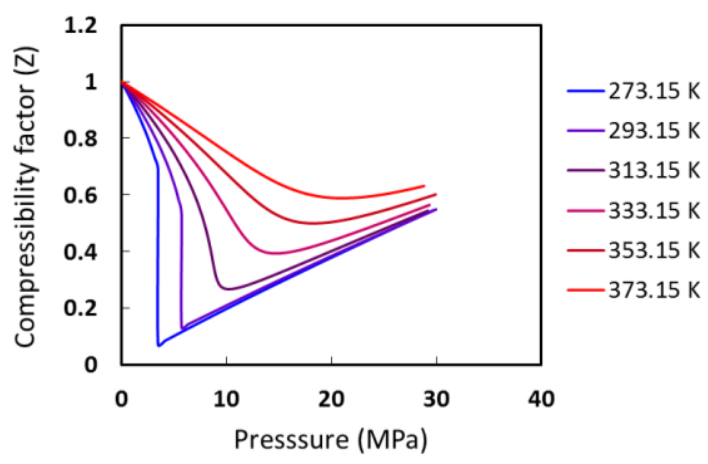

Figure 1 Deviation behavior of the $\mathrm{CO}_{2}$ under different temperatures and pressures (Data is obtained from the NIST Standard Reference Database 23 (REFPROP: Version 8.0.))

To tentatively solve the above-mentioned issues, this work first uses a dual-site Langmuir model to describe $\mathrm{scCO}_{2}$ adsorption behavior in coal by considering both the adsorbed phase and the absorbed (penetrated) phase. Then, the published data of high pressure $\mathrm{scCO}_{2}$ adsorption in two different coals are obtained from literature in order to validate the proposed model. Last, isosteric heats of adsorption for $\mathrm{scCO}_{2}$ are calculated analytically by considering the real gas behavior of $\mathrm{scCO}_{2}$ and the contribution of the adsorbed phase.

\section{Absolute adsorption model}

Coal swelling is a pronounced phenomenon associated with $\mathrm{CO}_{2}$ injection into coal seams, which can result in injectivity issues during field tests (White et al., 2005; Van Bergen, et al., 2006). Researchers have used different approaches such as dilatometric method, optical or strain gages, and X-ray and small-angle scattering techniques to study the coal swelling effects in a laboratory scale, but have not reached an agreement on whether the coal swelling is universal or not. Radlinski et al. (2009) found that coal microstructures were unaffected by exposure to $\mathrm{CO}_{2}$ over a period of days based on the SANS and USANS tests. Most other researchers agree that the uptake of $\mathrm{CO}_{2}$ in coal results in the swelling monotonically with pressure which can be modeled by Langmuir-type curves based on laboratory evidence (Levine, 1996; Palmer and Mansoori, 1998; Shi and Durucan, 2004a; Cui et al.., 2007; Pini et al.., 2009 \& 2010),

$\varepsilon_{s}=\varepsilon_{0} \cdot \frac{k_{s} P}{1+k_{s} P}$

where $\varepsilon_{s}$ is the swelling strain under specific pressure, P, $\varepsilon_{0}$ and $k_{s}$ are fitting coefficients.

Based on the assumption that coal swelling is induced by the $\mathrm{CO}_{2}$ penetration (absorption) in the macrostructure of coal, the dual-site model is used for describing both the $\mathrm{CO}_{2}$ adsorption and the $\mathrm{CO}_{2}$ absorption in coal as shown in equation (2) (Fornstedt et al., 1996; Graham et al., 1953; Larsen, 2004; Pini et al., 2010). Figure 2 shows how the $\mathrm{CO}_{2}$ phase changes before and after $\mathrm{CO}_{2}$ sorption: the absolute adsorption is the sum of net adsorption and absorption uptake. The dual-site model therefore combines both the adsorption and absorption content of $\mathrm{CO}_{2}$ in coal, represented by a Langmuir-type term. In addition, the absorption term essentially has similar properties with the coal swelling behavior. 
$n_{a}=n_{a d} \frac{K_{1}(T) P}{1+K_{1}(T) P}+n_{a b} \frac{K_{2}(T) P}{1+K_{2}(T) P}$

where $n_{a}$ is the absolute adsorption content under specific pressure, $\mathrm{P}, n_{a d}$ is the net adsorption content, $n_{a b}$ is the absorption content, $K_{1}(T)$ and $K_{2}(T)$ are corresponding Langmuir contents (( $K_{1}(T)=A_{1} \cdot \exp \left(-\frac{E_{1}}{R T}\right)$ and $\left.K_{2}(T)=A_{2} \cdot \exp \left(-\frac{E_{2}}{R T}\right)\right), \mathrm{T}$ represents temperature, $\mathrm{E}_{1}$ and $\mathrm{E}_{2}$ are corresponding adsorption energies, $A_{1}$ and $A_{2}$ are corresponding prefactors, $R$ is universal gas constant), $P$ is pressure.

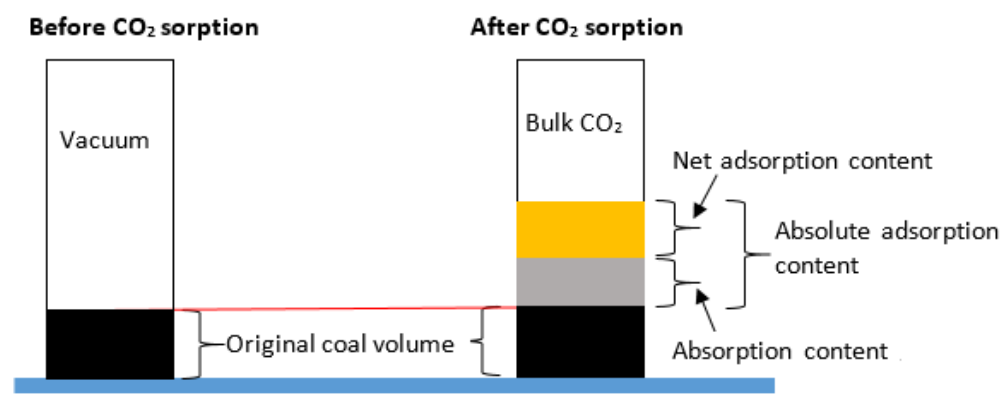

Figure 2 The difference of $\mathrm{CO}_{2}$-coal sorption system before and after $\mathrm{CO}_{2}$ adsorption.

If the absorbed and adsorbed phase can be weighted by a parameter, $\alpha$, and equation (2) is rearranged, the following form can be obtained,

$n_{a}=n_{\max } \cdot\left[(1-\alpha)\left(\frac{K_{1}(T) P}{1+K_{1}(T) P}\right)+\alpha\left(\frac{K_{2}(T) P}{1+K_{2}(T) P}\right)\right]$

where $\mathrm{n}_{\max }$ is the maximum adsorption capacity. Notably, the physical meaning of $n_{\max }$ in equation (3) is different form the conventional Langmuir equation which is composed of both the net adsorption content and the absorption content. The term "adsorbed" will be used in the following sections as a simplification which actually refers to both adsorbed and absorbed (penetrated) phases for $\mathrm{CO}_{2}$ in coal.

\section{Gibbs excess adsorption model and isosteric heat of adsorption}

\subsection{Gibbs excess adsorption model}

For a pure gas and solid sorption system, the excess adsorbed amount $\left(n_{e}\right)$ can be shown by the Gibbs equation (4) (Gibbs, 1878),

$n_{e}=n_{a}-V_{a} \cdot \rho_{g}=\mathrm{n}_{a}\left(1-\frac{\rho_{g}}{\rho_{a}}\right)$

where $n_{e}$ is the excess adsorption content, $n_{a}$ is the absolute adsorption content, $v_{a}$ is the total volume of both the absorbed and adsorbed phases, $\rho_{a}$ is the density of adsorbed phase and $\rho_{g}$ is the density of bulk phase under specific temperature and pressure. When the $V_{a}$ is very small, the contribution of the 
adsorbed phase can be neglected and $n_{e}$ is the approximation of the $n_{a}$ (Zhou et al., 2001). However, for a high pressure sorption system, the contribution of the adsorbed phase must be taken into consideration to physically interpret the abnormal gas adsorption behavior. For example, the observed adsorption uptake increases, reached maximum and then decreases with increasing gas pressure. Therefore, it is imperative to find a reasonable approach for obtaining the absolute isotherms from Gibbs excess isotherms for the gas-solid sorption system under high pressure and temperature.

Considering the accepted assumption that the density of the adsorbed phase can be treated as an unknown constant (Agarwal et al., 1988; Zhou et al., 2001; Do et al., 2003; Mertens, 2009; Stadie et al., 2012; Schell et al., 2012; Stadie et al., 2013 \& 2015; Tang et al., 2016), the volume of the adsorbed gas phase can be obtained by equation (5),

$V_{a}=\frac{n_{a}}{\rho_{a}}$

Combining with equation (3), equation (5) can be rewritten as,

$$
V_{a}=V_{\max } \cdot\left[(1-\alpha)\left(\frac{K_{1}(T) P}{1+K_{1}(T) P}\right)+\alpha\left(\frac{K_{2}(T) P}{1+K_{2}(T) P}\right)\right]
$$

where $V_{a}$ is the total volume of the adsorbed phase under specific temperature and pressure, $V_{\max }$ is the maximum volume at maximum adsorption content, $V_{\max }=n_{\max } / \rho_{a}$. Based on equations (3), (4) and (6), both excess adsorption $\left(n_{e}\right)$ and surface coverage $(\theta)$ equations can be obtained as shown in equation (7) and (8)

$$
\begin{aligned}
& n_{e}(P, T)=\left(n_{\text {max }}-V_{\text {max }} \cdot \rho_{g}\right) \cdot\left[(1-\alpha)\left(\frac{K_{1}(T) P}{1+K_{1}(T) P}\right)+\alpha\left(\frac{K_{2}(T) P}{1+K_{2}(T) P}\right)\right] \\
& \theta=\frac{\mathrm{n}_{\mathrm{a}}}{n_{\max }}=(1-\alpha) \frac{K_{1}(T) P}{1+K_{1}(T) P}+\alpha\left(\frac{K_{2}(T) P}{1+K_{2}(T) P}\right)
\end{aligned}
$$

If the observed adsorption isotherms (Gibbs excess adsorption isotherms) are obtained through isothermal adsorption tests, equation (7) is able to describe the adsorption behavior where the parameters $\left(V_{\max }, n_{\max }, K_{1}(T), K_{2}(T), \alpha\right)$ can be obtained via curve fitting. The absolute adsorption content can then be solved for via equation (5).

\subsection{Isosteric heat of adsorption}

Based on the Clausius-Clapeyron relationship (Clausius, 1850), it is known,

$$
\Delta H_{a d}=\left(\frac{d P}{d T}\right)_{n_{a}} \cdot T \cdot \Delta v=\left(\frac{d P}{d T}\right)_{n_{a}} \cdot T \cdot\left(v_{a}-v_{g}\right)
$$


where $\Delta H_{a d}$ is the isosteric heat of adsorption, $\Delta v\left(=\left(v_{a}-v_{g}\right)\right)$ is the volume change of the phase change, $v_{g}$ is the molar volume of the bulk gas phase, $v_{a}$ is the molar volume of the adsorbed phase, and $\mathrm{T}$ is temperature.

In order to obtain $\Delta H_{a d}$, the $\left(\frac{d P}{d T}\right)_{n_{a}}$ must be obtained first (Chakraborty et al., 2006; Stadie et al., 2015). Based on the surface coverage concept (equation (3)), the following relationship can be obtained using the chain rule (Mertens, 2009; Stadie et al., 2014 \& 2015),

$$
\left(\frac{d P}{d T}\right)_{n_{a}}=\left(\frac{\partial P}{\partial \theta}\right)_{n_{a}} \cdot\left(\frac{\partial \theta}{\partial K}\right)_{n_{a}} \cdot\left(\frac{\partial K}{\partial T}\right)_{n_{a}}
$$

Combining with equation (9) and (10) and applying the ideal gas law ( $\left.P v_{g}=R T\right)$, we can obtain one form of isosteric heats of adsorption mathematically (equation (11)),

$$
-\Delta H_{a d s\left(n_{a}\right), I G L}=\left(\frac{\partial P}{\partial \theta}\right)_{n_{a}} \cdot\left(\frac{\partial \theta}{\partial K}\right)_{n_{a}} \cdot\left(\frac{\partial K}{\partial T}\right)_{n_{a}} \cdot T \cdot\left(\frac{R T}{P}-\rho_{a}^{-1}\right)
$$

If we combine equation (10) and (11) and apply the real gas law, another analytical form of the isosteric heat of adsorption can be obtained (equation (12),

$$
-\Delta H_{a d s\left(n_{a}\right), R G L}=\left(\frac{\partial P}{\partial \theta}\right)_{n_{a}} \cdot\left(\frac{\partial \theta}{\partial K}\right)_{n_{a}} \cdot\left(\frac{\partial K}{\partial T}\right)_{n_{a}} \cdot T \cdot\left(\rho_{g}^{-1}-\rho_{a}^{-1}\right)
$$

Equation (12) and (13) are much easier to solve using the analytical approach. Equation (13) shows the analytical solution of $\left(\frac{d P}{d T}\right)_{n_{a}}$ (Mertens, 2009; Stadie et al., $\left.2013 \& 2015\right)$,

$$
\left(\frac{\partial P}{\partial \theta}\right)_{n_{a}} \cdot\left(\frac{\partial \theta}{\partial K}\right)_{n_{a}} \cdot\left(\frac{\partial K}{\partial T}\right)_{n_{a}}=\frac{\frac{(1-\alpha) P}{\left(1+K_{1}(T) P\right)^{2}} \cdot \frac{-E_{1} K_{1}(T)}{R T^{2}}+\frac{\alpha P}{\left(1+K_{2}(T) P\right)^{2}} \cdot \frac{-E_{2} K_{2}(T)}{R T^{2}}}{\frac{(1-\alpha) K_{1}(T)}{\left(1+K_{1}(T) P\right)^{2}}+\frac{\alpha K_{2}(T)}{\left(1+K_{2}(T) P\right)^{2}}}
$$

Using the dual-site Langmuir adsorption model, absolute adsorption isotherms can be obtained from the excess adsorption isotherms. The isosteric heat of adsorption can then be calculated considering the real gas behavior and the contribution of the adsorbed phase, neither are considered in the classic Clausius-Clapeyron approximation.

\section{Data set acquisition and processing}

High pressure (over 7.4 MPa) $\mathrm{scCO}_{2}$ adsorption isotherms in coals are limited, and only two sets of data are directly retrieved from the literature (Song et al., 2015; Ottiger et al., 2006). These data were measured using the gravimetric approach to obtain the $\mathrm{scCO}_{2}$ sorption isotherms in dry coal under different temperatures and pressures $(>=15 \mathrm{MPa})$. Detailed information about these tests can be found in the original publications (Song et al., 2015; Ottiger et al., 2006). The pertinent data from these papers are shown in Figure 3. 

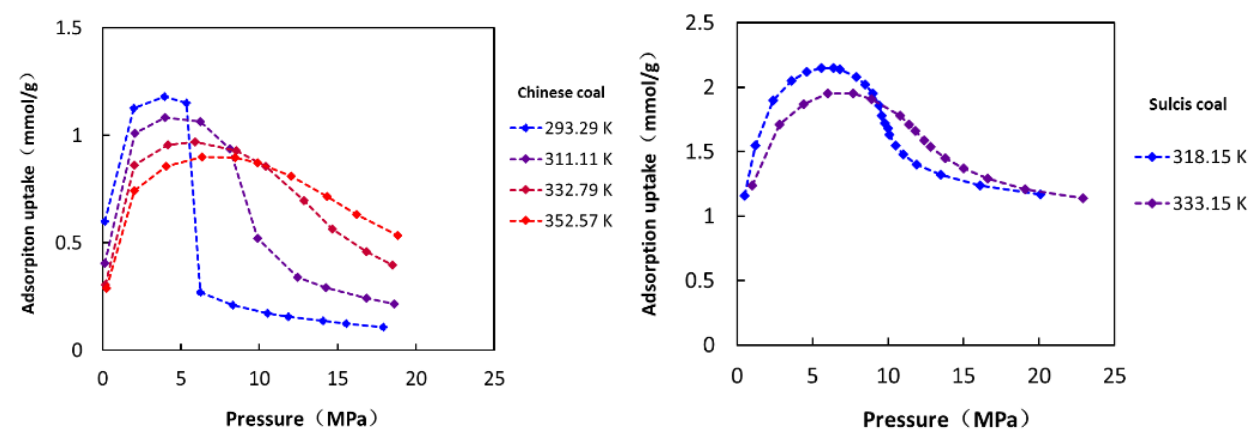

Figure 3 Experimental data retrieved from Song et al. (2015), Ottiger et al. (2006); the dotted line is to connect data points for visualization.

The observed adsorption isotherms under different temperatures are fitted simultaneously using equation (7) within the limits of the fitting parameters $\left(0<\mathrm{n}_{\max }<100 \mathrm{mmol} / \mathrm{g}, 0<\mathrm{V}_{\max }<100 \mathrm{~cm}^{3} / \mathrm{g}\right.$, $\left.0<\alpha<1,10 \mathrm{~kJ} / \mathrm{mol}<\mathrm{E}_{1}, \mathrm{E}_{2}<100 \mathrm{~kJ} / \mathrm{mol}, 0<\mathrm{A}_{1}, \mathrm{~A}_{2}\right)$. The test data is processed using the Universal Global Optimization (UGO) method of the Auto2Fit software (7D-soft High Technology Inc., China), and the UGO can find the global maximum/minimal value of any functions without using the initial start values. The obtained fitting parameters are shown in Table 1.

Table 1 Fitting parameters (equation (7)) for observed adsorption isotherms using four adsorption isotherms

\begin{tabular}{|l|c|c|c|c|c|c|c|c|}
\hline \multicolumn{1}{|c|}{ Samples } & Temperatures $(\mathrm{K})$ & $\mathrm{n}_{\max }(\mathrm{mmol} / \mathrm{g})$ & $\mathrm{V}_{\max }\left(\mathrm{cm}^{3} / \mathrm{g}\right)$ & $\alpha$ & $\mathrm{E}_{1}(\mathrm{~kJ} / \mathrm{mol})$ & $\mathrm{E}_{2}(\mathrm{~kJ} / \mathrm{mol})$ & $\mathrm{A}_{1}\left(\mathrm{MPa}^{-1}\right)$ & $\mathrm{A}_{2}\left(\mathrm{MPa}{ }^{-1}\right)$ \\
\hline Chinese coal & $\begin{array}{c}293.29,311.11, \\
332.79,352.55\end{array}$ & 1.6675 & 0.0752 & 0.4941 & 26.702 & 25.497 & $2.15 \mathrm{E}-04$ & $1.10 \mathrm{E}-05$ \\
\hline Sulcis coal & $318.15,333.15$ & 6.3932 & 0.2220 & 0.6612 & 28.019 & 36.940 & $5.16 \mathrm{E}-05$ & $1.54 \mathrm{E}-08$ \\
\hline
\end{tabular}

Once all the fitting parameters are obtained from fitting the observed adsorption isotherms using equation (7), the absolute adsorption isotherm can be calculated using equation (5). Then, the isosteric heat of adsorption can also be obtained using equations (11) \& (12).

\section{Modeling results and discussions}

\subsection{Observed and absolute adsorption isotherms}

Figure 4 shows the dual-site Langmuir model fits observed adsorption isotherms very well. It is clear that the predicted absolute adsorption content of $\mathrm{scCO}_{2}$ increases continuously with increasing pressures. The absolute adsorption content is much higher than Gibbs excess adsorption isotherms. The distinguishable difference between observed and absolute adsorption isotherm implies the significant contribution of the adsorbed layer of $\mathrm{scCO}_{2}$ in coal for absolute adsorption content. 

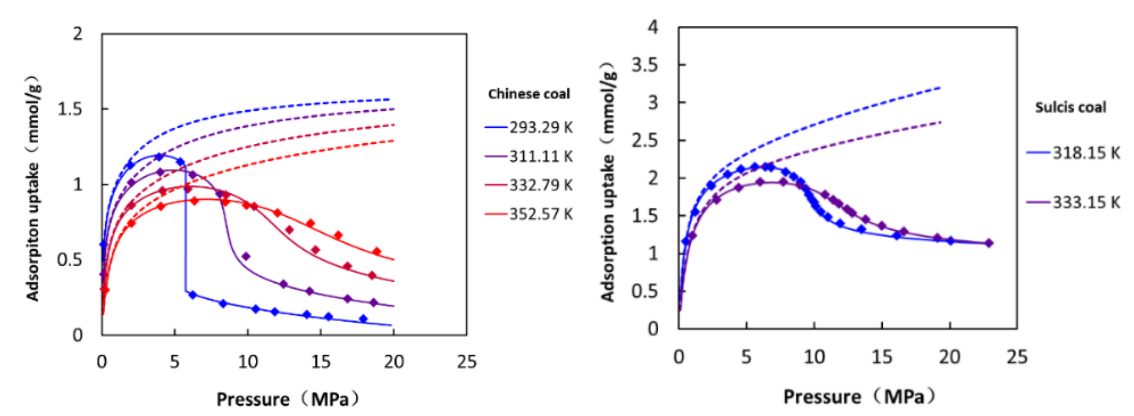

Figure 4 Fitting adsorption isotherms using dual-site Langmuir model for five coals; solid line: Gibbs excess fitting (equation (8)) and dotted line: absolute adsorption uptake (equation (5))

For both coals, there are consistent crossovers of the observed adsorption isotherms under different temperatures after the observed adsorption content reached the maximum value. After the crossover, the observed adsorption content at higher temperatures is greater than at low temperatures under the same pressure. However, the temperature-dependent property of adsorption uptake under different temperatures can be shown via the absolute adsorption uptake, where the higher the temperature the lower the adsorption uptake. The abnormal crossover phenomenon of the observed adsorption isotherms appears because the pressure is used as the independent variable, instead of the density of $\mathrm{scCO}_{2}$. Figure 5 shows two components of Gibbs excess adsorption uptake (equation (7)), surface coverage $(\Theta)$ and the term $\left(n_{\max }-V_{\max } * \rho(P, T)\right.$, as a function of pressure and density. When the pressure is treated as a variable, the term $\left(n_{\max }-V_{\max }{ }^{*} \rho(P, T)\right)$ show temperature as well as pressure dependency feature because of the density of $\mathrm{scCO}_{2}, \rho(P, T)$. However, when the pressure is treated as a density, the term $\left(n_{\max }-V_{\max } * \rho(P, T)\right.$ only show the pressure-independency feature. Therefore, the cross-over is simply caused by the PVT behavior of $\mathrm{scCO}_{2}$.
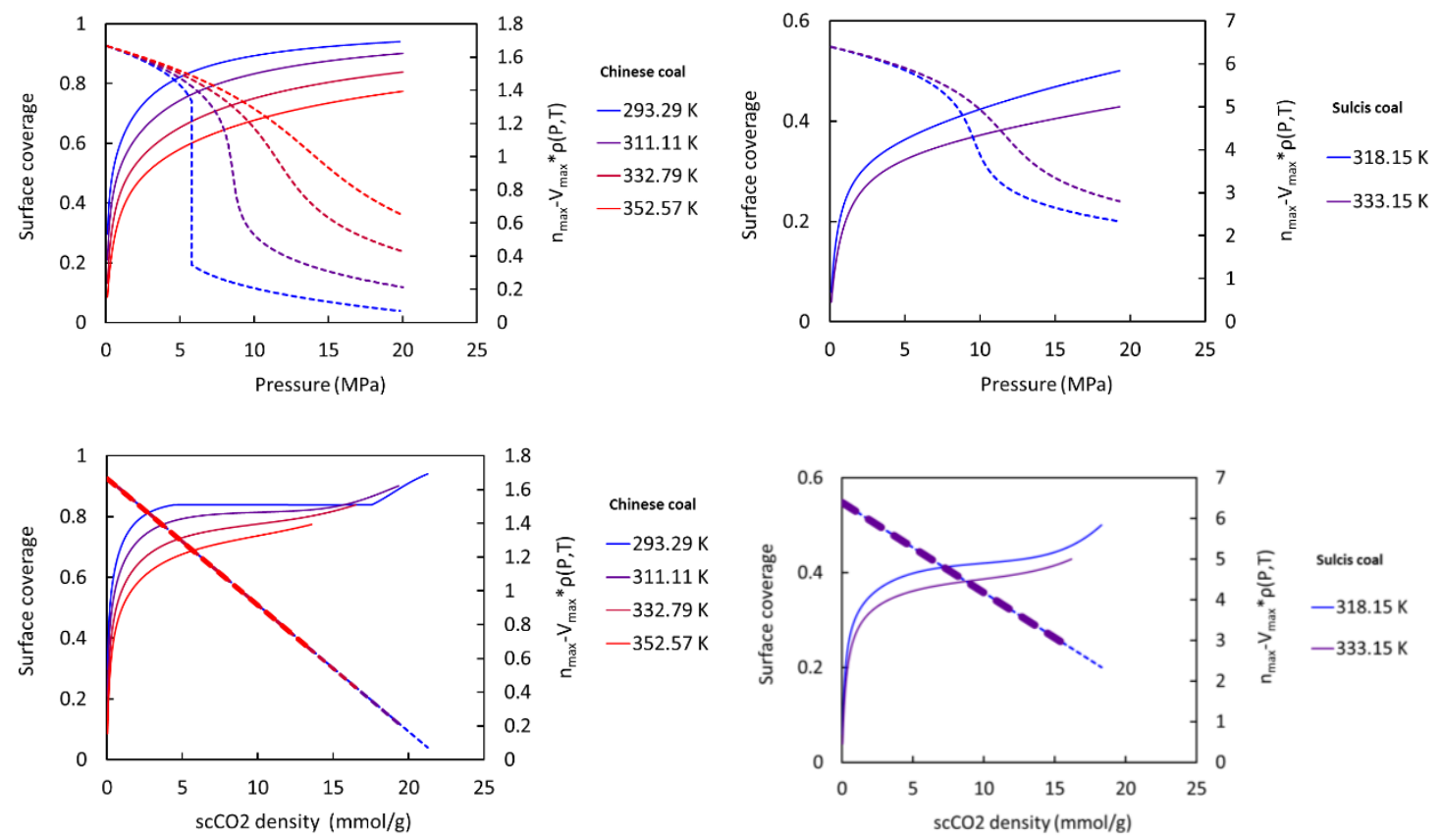

Figure 5 Surface coverage (solid line, left axial) and the term $\left(n_{\max }-V_{\max } * \rho(P, T)\right)$ (dotted lines, right axial) with increasing pressure (density) for both Chinese and Sulcis coals 


\subsection{Adsorption isotherm prediction}

For geological storage of carbon dioxide in subsurfaces such as unminable coal seams and shale formations, one of the crucial issues is to estimate the storage capacity of carbon dioxide under real geological conditions. With increasing depth, both in-situ reservoir pressure and geothermal effect become pronounced, and there will be a phase change of carbon dioxide from subcritical status to supercritical status. Thus, carbon dioxide storage capacity must take high pressure and high temperature conditions into consideration. However, it is impractical to measure all isotherms under different temperatures. Therefore, finding an adsorption model capable to predict higher temperature adsorption isotherms using lower temperature data pique researchers' interests.

Predicting isotherms under different temperatures are possible using the proposed model because the temperature dependency of adsorption isotherms are only exhibited through the Langmuir constant $\left(K_{1}(T)\right.$ and $K_{2}(T)$ in equations ( 3 and 7$\left.)\right)$. Figure 6 (left part) shows that the predicted adsorption isotherms have the same feature of the observed adsorption isotherms, where both the crossovers and the abnormal phenomenon (the higher the temperature the high the observed adsorption uptake) occur. When the adsorption isotherms are plotted as a function of bulk density, the crossovers disappear, which means the higher the temperature the lower the observed adsorption uptake. This behavior can also be shown in the predicted adsorption isotherms (Figure 6, right part).
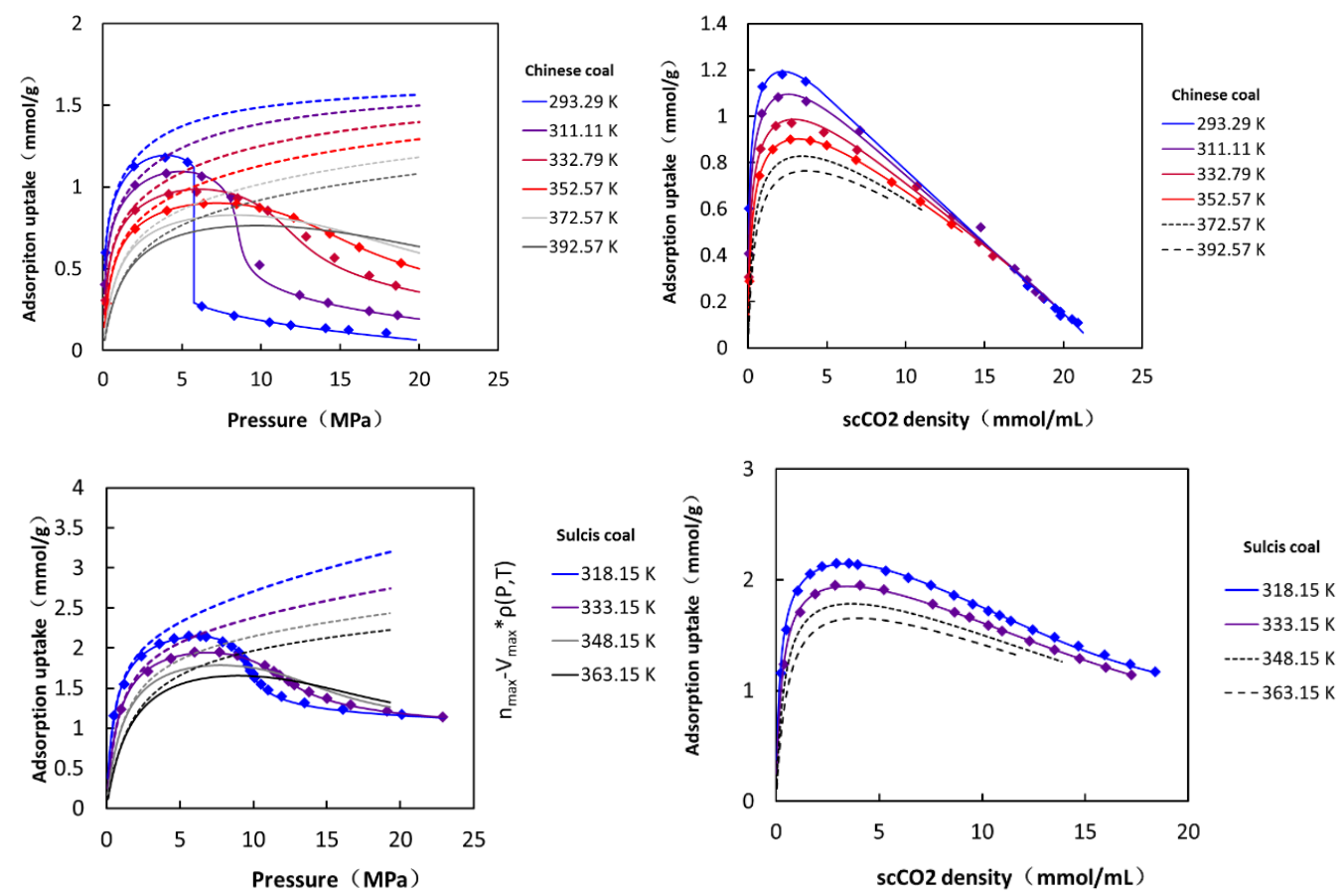

Figure 6 Prediction of adsorption isotherms (black lines) beyond test data; left part: adsorption uptake as a function of pressure; right part: adsorption uptake as a function of bulk density.

\subsection{Confidence of the predicted adsorption isotherms}

In order to validate the prediction ability of the proposed model, the Chinese coal sample is taken as an example to show the confidence of the predicted adsorption isotherms. First, only three adsorption isotherms from the four isotherms are fitted using the proposed method. Then, the predicted 
adsorption isotherms are compared with the test data to see the difference. Table 2 shows that the fitting parameters use only three adsorption isotherms. Figure 7 shows that all predicted isotherms are consistent with test data. The predicted adsorption isotherms beyond test data are approximately the same. This also means the best-fit parameter can only be achieved using a large set of measured data.

Table 2 Fitting parameters (equation (7)) for observed adsorption isotherms using only three adsorption isotherms

\begin{tabular}{|c|c|c|c|c|c|c|c|c|c|}
\hline Samples & Fitting isotherms (K) & $\begin{array}{c}\text { Predicted } \\
\text { isotherms (K) }\end{array}$ & $\mathrm{n}_{\max }(\mathrm{mmol} / \mathrm{g})$ & $\mathrm{V}_{\max }\left(\mathrm{cm}^{3} / \mathrm{g}\right)$ & $\alpha$ & $\mathrm{E} 1(\mathrm{~kJ} / \mathrm{mol})$ & $\mathrm{E} 2(\mathrm{~kJ} / \mathrm{mol})$ & $\mathrm{A} 1\left(\mathrm{MPa}^{-1}\right)$ & $\mathrm{A} 2\left(\mathrm{MPa}^{-1}\right)$ \\
\hline \multirow{3}{*}{ Chinese coal } & $293.29,311.11,332.79$ & $352.55,392.57$ & 1.6837 & 0.0760 & 0.5345 & 26.593 & 27.244 & $6.08 \mathrm{E}-06$ & $1.54 \mathrm{E}-04$ \\
\hline & $293.29,332.79,352.55$ & $311.11,392.57$ & 1.6521 & 0.0745 & 0.5033 & 27.632 & 24.941 & $1.66 \mathrm{E}-04$ & $1.44 \mathrm{E}-05$ \\
\hline & $293.29,311.11,352.55$ & $332.79,392.57$ & 1.6471 & 0.0742 & 0.5050 & 26.962 & 25.192 & 2.05E-04 & $1.41 \mathrm{E}-05$ \\
\hline
\end{tabular}

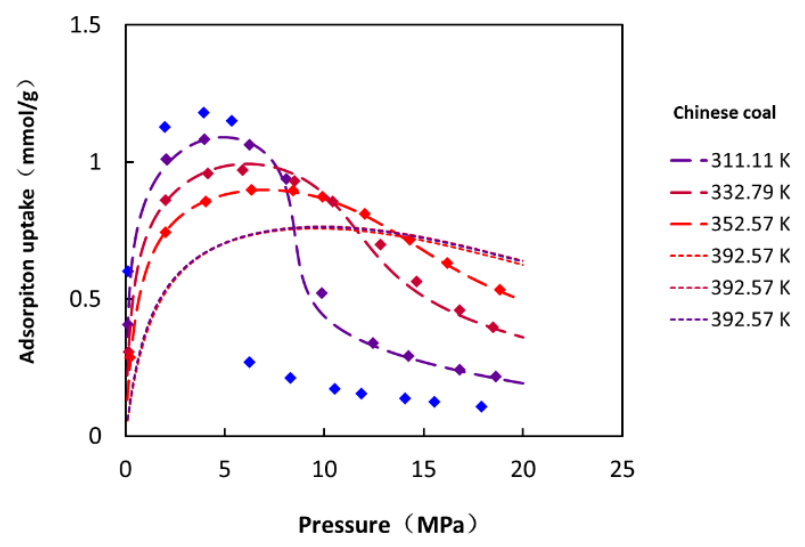

Figure 7 Adsorption isotherms comparison between predicted data using three adsorption isotherms (dotted lines). Solid symbol represents test data.

\subsection{Thermodynamic analysis of isotherms}

Figure 8 shows isosteric heats of adsorpiton calcualted using equations (11) and (12) and it can be seen that (i) the isosteric heat of adsorption decreases with increasing absolute adsorption uptake and (ii) temperature dependence of the isosteric heat of adsorption. It is also clear that the isosteric heats of adsorption using the ideal gas law are always higher than that using the real gas law at the same temperature. This means the isosteric heats of adsorption using the ideal gas law always overestimates the isosteric heat of adsorption. Both the temperature dependency and adsorption uptake dependency of the isosteric heat can also be readily shown using the proposed approach. 

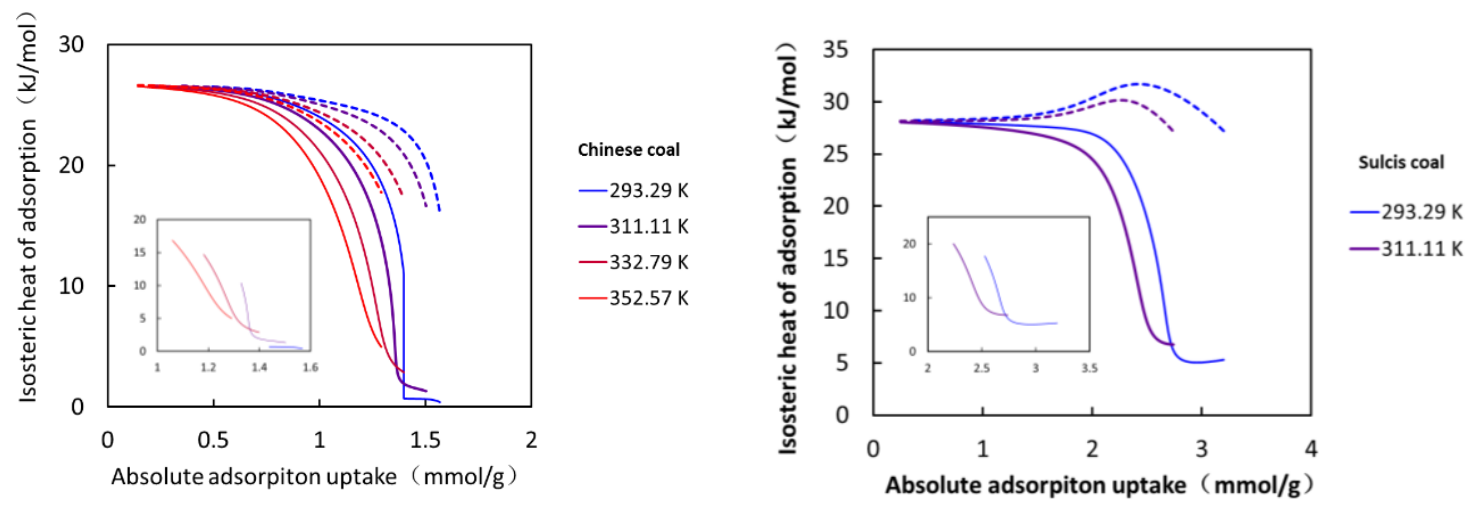

Figure 8 Comparison of different isosteric heats of adsorption for $\mathrm{scCO}_{2}$ in coal: isosteric heat of adsorptions using ideal gas law (dotted lines) and real gas law (solid lines), and the gas phases are supercritical and liquid in the magnified area.

After carbon dioxide becomes $\mathrm{scCO}_{2}$ (or liquid $\mathrm{CO}_{2}$ ), the heat of adsorption shows different behaviors as shown in the magnified area in Figure 8. When the $\mathrm{CO}_{2}$ is in liquid phase, the isosteric heat of adsorption is the lowest compared with $\mathrm{scCO}_{2}$. When the $\mathrm{CO}_{2}$ becomes $\mathrm{scCO}_{2}$, the isosteric heat of adsorption decreases with increasing absolute adsorption uptake but there are crossovers of isosteric heat of adsorption under different temperatures, which has not been reported in literature. This can be attributed to the enhanced interaction among the adsorbed phase over the coal surface at a higher density (Schaef et al, 2013). Figure 9 shows the density at low temperatures is much higher than that at high temperatures for $\mathrm{scCO}_{2}$, which may strengthen the enhanced interaction effect.

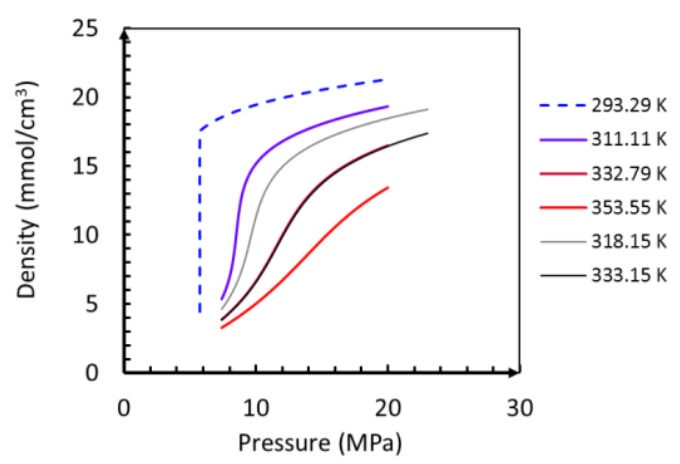

Figure 9 Density of liquid and $\mathrm{scCO}_{2}$; dotted line represents liquid carbon dioxide and solid line represents $\mathrm{ScCO}_{2}$

\section{Implications for geological carbon dioxide storage}

Carbon dioxide storage in deep unminable coal seams and deep shale formations are two promising geological sites for onshore carbon sequestration. Since the adsorption phase of carbon dioxide in coal is one of the main components of the total carbon dioxide gas-in-place in the subsurface, the accurate prediction of adsorption carbon dioxide in coal is crucial. With the increasing reservoir depth, high pressure and high temperature geological situations have to be considered. Such geological conditions result in the change of carbon dioxide from subcritical phase to supercritical phase, and an optimized model is needed to analyze such behavior. The proposed dual-site Langmuir model can describe both the observed adsorption and the absolute adsorption of sub- and super-critical carbon dioxide in coal. In 
order to accurately assess the storage capacity of $\mathrm{scCO}_{2}$ in coal, equation (14) should be used for the total carbon dioxide gas-in-place (GIP) in the subsurface (Tang et al., 2016),

$$
G I P_{c o_{2}}=n_{e}+V_{t o t} \rho_{g}
$$

Where $\mathrm{n}_{\mathrm{e}}$ is the observed adsorption uptake (Gibbs excess adsorption uptake), $V_{\text {tot }}$ is the total pore space of coal measured by Helium intrusion test, and $\rho_{g}$ is the density of bulk gas. Equation (14) supports the fact that if the observed adsorption isotherms are obtained from laboratory tests, the carbon dioxide storage capacity can be accurately assessed and there is no need to differentiate absolute adsorption content from observed adsorption isotherms. However, this is only valid for estimating the total storage capacity of coal seams. In order to understand the existing status of injected carbon dioxide in coal and carbon dioxide transport behavior under reservoir conditions, the true ratio between bulk carbon dioxide and the adsorbed phase must be known. Using the observed adsorption isotherms (Gibbs excess adsorption isotherms) will always underestimate the true content of the adsorbed phase as shown in Figure 4. The dual-site Langmuir model can solve this problem by extrapolating the true content of the adsorbed phase (equation (3)) from observed adsorption isotherms. Furthermore, for large scale carbon dioxide injection tests in deep coal seams, one of the fundamental issues is to understand how the injected carbon dioxide transports within the coal matrix (Tang et al., 2015). Since carbon dioxide exists in coal seams mainly in two states (free gas and adsorbed phase), the adsorbed phase influences the transport behavior of carbon dioxide because it not only occupies space in nanopores but also interacts with pore walls. It has been found that the adsorbed gas phase significantly affects adsorptive gas (methane) transport in coal seams and shale formations (Yu et al., 2014; Akkutlu et al., 2012; Civan et al., 2011; Singh et al., 2016; Naraghi et al., 2015; Wu et al., 2016). This situation will also occur with respect to carbon dioxide transport in coal. Therefore, in order to build a reasonable gas transport model for carbon dioxide transport in coal seams, the first step is to obtain the true ratio of the free phase to the adsorbed phase (Tang et al., 2016). The proposed dual-site Langmuir adsorption model makes this possible.

\section{Conclusions}

This work uses a dual-site Langmuir adsorption model to describe high pressure carbon dioxide adsorption in coal by considering both the adsorbed and absorbed phases. Then, the isosteric heat of adsorption are calculated analytically by considering both the real gas behavior and the adsorbed gas phase. Last, the published data for high pressure carbon dioxide adsorption in coal are utilized to verify the proposed model.

Modeling results reveal the proposed model can not only reasonably address observed test phenomena but also has the intrinsic ability to extrapolate adsorption isotherms under different temperatures beyond test data. It was found that the crossovers of the observed adsorption isotherms under different temperatures are caused by the changing volume of the adsorbed and absorbed phases during the adsorption process.

Both the temperature dependence and absolute adsorption uptake dependence of the isosteric heat of adsorption are readily investigated for $\mathrm{scCO}_{2}$ in coal; for subcritical carbon dioxide, the higher the temperature and the higher the absolute adsorption uptake, the lower the isosteric heat of adsorption. The gas behavior significantly affects the quantity of the isosteric heat of adsorption: the isosteric heat 
of adsorption using the ideal gas law always overestimates the isosteric heat of adsorption for $\mathrm{scCO}_{2}$ in coal. For $\mathrm{scCO}_{2}$ adsorption in coal, there exists an abnormal phenomenon that the higher the temperature the higher the isosteric heat of adsorption, which has not been previously reported in the literature.

The proposed adsorption model lays the foundation for accurately estimating the storage capacity of carbon dioxide, differentiating the true ratio between the adsorbed phase and bulk phases and developing gas transport models that consider the adsorbed phase effect. The thermodynamic analysis is useful for interpreting temperature related phenomena associated with carbon dioxide adsorption in coal as well as shale gas reservoirs.

\section{Acknowledgements}

Financial assistance for this work was provided by the U.S. Department of Energy through the National Energy Technology Laboratory's Program under Contract No. DE-FE0006827.

\section{Reference}

Agarwal, R. K., \& Schwarz, J. A. (1988). Analysis of high pressure adsorption of gases on activated carbon by potential theory. Carbon, 26(6), 873-887.

Akkutlu, I. Y., \& Fathi, E. (2012). Multiscale gas transport in shales with local kerogen heterogeneities. SPE Journal, 17(04), 1-002.

Bae, J. S., \& Bhatia, S. K. (2006). High-pressure adsorption of methane and carbon dioxide on coal. Energy \& Fuels, 20(6), 2599-2607.

Baran, P., Cygankiewicz, J., \& Zarębska, K. (2013). Carbon dioxide sorption on Polish ortholignite coal in low and elevated pressure. Journal of $\mathrm{CO} 2$ Utilization, 3, 44-48.

Benson, S. M., \& Cole, D. R. (2008). CO2 sequestration in deep sedimentary formations. Elements, 4(5), 325-331.

Busch, A., \& Gensterblum, Y. (2011). CBM and CO2-ECBM related sorption processes in coal: a review. International Journal of Coal Geology, 87(2), 49-71.

Clausius, R. (1850), Ueber die bewegende Kraft der Wärme und die Gesetze, welche sich daraus für die Wärmelehre selbst ableiten lassen. Ann. Phys., 155: 500-524. doi:10.1002/andp.18501550403.

Connell, L. D., Pan, Z., Shangzhi, M., Camilleri, M., Down, D., Carras, J., ... \& Lupton, N. (2013). Description of a CO 2 Enhanced Coal Bed Methane Field Trial Using a Multi-Lateral Horizontal Well. Energy Procedia, 37, 6760-6768.

Cui, X.J., Bustin, R.M., Chikatamarla, L., 2007. Adsorption-induced coal swelling and stress: implications for methane production and acid gas sequestration into coal seams. J. Geophys. Res. [Solid Earth] 112, $1-16$.

Civan, F., Rai, C. S., \& Sondergeld, C. H. (2011). Shale-gas permeability and diffusivity inferred by improved formulation of relevant retention and transport mechanisms. Transport in Porous Media, 86(3), 925-944. 
Chakraborty, A., Saha, B. B., Koyama, S., \& Ng, K. C. (2006). On the thermodynamic modeling of the isosteric heat of adsorption and comparison with experiments. Applied physics letters, 89(17), 171901.

Day, S., Fry, R., \& Sakurovs, R. (2008). Swelling of Australian coals in supercritical CO 2. International Journal of Coal Geology, 74(1), 41-52.

Day, S., Duffy, G., Sakurovs, R., \& Weir, S. (2008). Effect of coal properties on CO 2 sorption capacity under supercritical conditions. International Journal of Greenhouse Gas Control, 2(3), 342-352.

Do, D. D., \& Do, H. D. (2003). Adsorption of supercritical fluids in non-porous and porous carbons: analysis of adsorbed phase volume and density. Carbon, 41(9), 1777-1791.

Do, D. D., \& Do, H. D. (1997). A new adsorption isotherm for heterogeneous adsorbent based on the isosteric heat as a function of loading. Chemical engineering science, 52(2), 297-310.

Fitzgerald, J. E., Pan, Z., Sudibandriyo, M., Robinson Jr, R. L., Gasem, K. A. M., \& Reeves, S. (2005). Adsorption of methane, nitrogen, carbon dioxide and their mixtures on wet Tiffany coal. Fuel, 84(18), 2351-2363.

Figueroa, J. D., Fout, T., Plasynski, S., Mcllvried, H., \& Srivastava, R. D. (2008). Advances in CO 2 capture technology - the US Department of Energy's Carbon Sequestration Program. International journal of greenhouse gas control, 2(1), 9-20.

Grubb, M. (1995). Seeking fair weather: ethics and the international debate on climate change. International Affairs (Royal Institute of International Affairs 1944), 463-496.

Goodman, A. L., Busch, A., Duffy, G. J., Fitzgerald, J. E., Gasem, K. A. M., Gensterblum, Y., ... \& Robinson, R. L. (2004). An inter-laboratory comparison of CO2 isotherms measured on Argonne premium coal samples. Energy \& Fuels, 18(4), 1175-1182.

Goodman, A. L., Busch, A., Bustin, R. M., Chikatamarla, L., Day, S., Duffy, G. J., ... \& Jing, C. (2007). Interlaboratory comparison II: $\mathrm{CO} 2$ isotherms measured on moisture-equilibrated Argonne premium coals at $55 \mathrm{C}$ and up to $15 \mathrm{MPa}$. International Journal of Coal Geology, 72(3), 153-164.

Gensterblum, Y., Van Hemert, P., Billemont, P., Battistutta, E., Busch, A., Krooss, B. M., ... \& Wolf, K. H. (2010). European inter-laboratory comparison of high pressure CO2 sorption isotherms II: natural coals. International Journal of Coal Geology, 84(2), 115-124.

Gunter, W. D., Mavor, M. J., \& Robinson, J. R. (2004, September). CO2 storage and enhanced methane production: field testing at Fenn-Big Valley, Alberta, Canada, with application. In Proceedings of the 7th International Conference on Greenhouse Gas Control Technologies (GHGT-7) (pp. 413-422).

Gibbs, J. W. (1878). On the equilibrium of heterogeneous substances. American Journal of Science, (96), 441-458.

Gilliland, E. S., Ripepi, N., Conrad, M., Miller, M. J., \& Karmis, M. (2013). Selection of monitoring techniques for a carbon storage and enhanced coalbed methane recovery pilot test in the Central Appalachian Basin. International Journal of Coal Geology, 118, 105-112.

Godec, M., Koperna, G., \& Gale, J. (2014). CO 2-ECBM: A Review of its Status and Global Potential. Energy Procedia, 63, 5858-5869. 
Herbst, A., \& Harting, P. (2002). Thermodynamic description of excess isotherms in high-pressure adsorption of methane, argon and nitrogen. Adsorption, 8(2), 111-123.

Herzog, H. J. (2001). Peer reviewed: what future for carbon capture and sequestration?. Environmental science \& technology, 35(7), 148A-153A.

Hedges, S. W., Soong, Y., McCarthy Jones, J. R., Harrison, D. K., Irdi, G. A., Frommell, E. A., ... \& Brown, T. D. (2005). CO2 Sequestration in Unmineable Coal Seams: Potential Environmental Impacts (No. DOE/NETL-IR-2005-215; NETL-TPR-1225). National Energy Technology Laboratory (NETL), Pittsburgh, PA, Morgantown, WV, and Albany, OR.

Jakubov, T.S., Mainwaring, D.E., 2002. Adsorption-induced dimensional changes of solids. PCCP 4, 56785682.

Krooss, B. M., Van Bergen, F., Gensterblum, Y., Siemons, N., Pagnier, H. J. M., \& David, P. (2002). Highpressure methane and carbon dioxide adsorption on dry and moisture-equilibrated Pennsylvanian coals. International Journal of Coal Geology, 51(2), 69-92.

Larsen, J. W. (2004). The effects of dissolved CO2 on coal structure and properties. International Journal of Coal Geology, 57(1), 63-70.

Levine, J., 1996. Model study of the influence of matrix shrinkage on absolute permeability of coal bed reservoirs. In: Gayer, R., Harris, I. (Eds.), Coalbed Methane and Coal Geology, vol. 109. Geological Society Special Publication, London, pp. 197-212.

Luo, X., Wang, S., Wang, Z., Jing, Z., Lv, M., Zhai, Z., \& Han, T. (2015). Adsorption of methane, carbon dioxide and their binary mixtures on Jurassic shale from the Qaidam Basin in China. International Journal of Coal Geology, 150, 210-223.

Mazzotti, M., Pini, R., \& Storti, G. (2009). Enhanced coalbed methane recovery. The Journal of Supercritical Fluids, 47(3), 619-627.

Mertens, F. O. (2009). Determination of absolute adsorption in highly ordered porous media. Surface Science, 603(10), 1979-1984.

Metz, B., Davidson, O., de Coninck, H., Loos, M., \& Meyer, L. (2005). Carbon dioxide capture and storage.

Morgan, J., Dagnet, Y., \& Tirpak, D. (2014). Elements and ideas for the 2015 Paris agreement. Washington, DC: Agreement for Climate Transformation.

Moreira, M. A., Ribeiro, A. M., Ferreira, A. F., \& Rodrigues, A. E. (2017). Cryogenic pressure temperature swing adsorption process for natural gas upgrade. Separation and Purification Technology, 173, 339-356.

Naraghi, M. E., \& Javadpour, F. (2015). A stochastic permeability model for the shale-gas systems. International Journal of Coal Geology, 140, 111-124.

Orr, F. M. (2009). Onshore geologic storage of CO2. Science, 325(5948), 1656-1658.

Ozdemir, E., Morsi, B. I., \& Schroeder, K. (2003). Importance of volume effects to adsorption isotherms of carbon dioxide on coals. Langmuir, 19(23), 9764-9773. 
Ottiger, S., Pini, R., Storti, G., Mazzotti, M., Bencini, R., Quattrocchi, F., ... \& Deriu, G. (2006). Adsorption of pure carbon dioxide and methane on dry coal from the Sulcis Coal Province (SW Sardinia, Italy). Environmental Progress, 25(4), 355-364.

Pan, Z., \& Connell, L. D. (2007). A theoretical model for gas adsorption-induced coal swelling. International Journal of Coal Geology, 69(4), 243-252.

Pan, Z., Connell, L. D., \& Camilleri, M. (2010). Laboratory characterisation of coal reservoir permeability for primary and enhanced coalbed methane recovery. International Journal of Coal Geology, 82(3), 252261.

Pini, R. (2014). Interpretation of net and excess adsorption isotherms in microporous adsorbents. Microporous and Mesoporous Materials, 187, 40-52.

Pan, H., Ritter, J. A., \& Balbuena, P. B. (1998). Examination of the approximations used in determining the isosteric heat of adsorption from the Clausius-Clapeyron equation. Langmuir, 14(21), 6323-6327.

Palmer, I., Mansoori, J., 1998. How permeability depends on stress and pore pressure in coalbeds: a new model. SPE Reserv. Eval. Eng. 1, 539-544.

Pini, R., Ottiger, S., Burlini, L., Storti, G., \& Mazzotti, M. (2010). Sorption of carbon dioxide, methane and nitrogen in dry coals at high pressure and moderate temperature. International Journal of Greenhouse Gas Control, 4(1), 90-101.

Pini, R., Ottiger, S., Burlini, L., Storti, G., Mazzotti, M., 2009. Role of adsorption and swelling on the dynamics of gas injection in coal. J. Geophys. Res. [Solid Earth] 114, B04203.

Radlinski, A. P., Busbridge, T. L., Gray, E. M., Blach, T. P., Cheng, G., Melnichenko, Y. B., ... \& Esterle, J. (2009). Dynamic micromapping of CO2 sorption in coal. Langmuir, 25(4), 2385-2389.

Romanov, V. N., Goodman, A. L., \& Larsen, J. W. (2006). Errors in CO2 adsorption measurements caused by coal swelling. Energy \& fuels, 20(1), 415-416.

Reucroft, P. J., \& Sethuraman, A. R. (1987). Effect of pressure on carbon dioxide induced coal swelling. Energy \& Fuels, 1(1), 72-75.

Ripepi, N. S. (2009). Carbon dioxide storage in coal seams with enhanced coalbed methane recovery: geologic evaluation, capacity assessment and field validation of the central appalachian basin (Doctoral dissertation, Virginia Polytechnic Institute \& State University).

Sams, W. N., Bromhal, G., Jikich, S., Ertekin, T., \& Smith, D. H. (2005). Field-project designs for carbon dioxide sequestration and enhanced coalbed methane production. Energy \& fuels, 19(6), 2287-2297.

Sakurovs, R., Day, S., Weir, S., \& Duffy, G. (2007). Application of a modified Dubinin-Radushkevich equation to adsorption of gases by coals under supercritical conditions. Energy \& fuels, 21(2), 992-997.

Stevens, S. H., Spector, D., \& Riemer, P. (1998, January). Enhanced coalbed methane recovery using CO2 injection: worldwide resource and $\mathrm{CO} 2$ sequestration potential. In SPE International Oil and Gas Conference and Exhibition in China. Society of Petroleum Engineers. 
Siemons, N., \& Busch, A. (2007). Measurement and interpretation of supercritical CO2 sorption on various coals. International Journal of Coal Geology, 69(4), 229-242.

Sudibandriyo, M., Pan, Z., Fitzgerald, J. E., Robinson, R. L., \& Gasem, K. A. (2003). Adsorption of methane, nitrogen, carbon dioxide, and their binary mixtures on dry activated carbon at $318.2 \mathrm{~K}$ and pressures up to 13.6 MPa. Langmuir, 19(13), 5323-5331.

Song, Y., Xing, W., Zhang, Y., Jian, W., Liu, Z., \& Liu, S. (2015). Adsorption isotherms and kinetics of carbon dioxide on Chinese dry coal over a wide pressure range. Adsorption, 21(1-2), 53-65.

Shi, J.Q., Durucan, S., 2004a. Drawdown induced changes in permeability of coalbeds: a new interpretation of the reservoir response to primary recovery. Transp. Porous Media 56, 1-16.

Schaef, H. T., Glezakou, V. A., Owen, A. T., Ramprasad, S., Martin, P. F., \& McGrail, B. P. (2013). Surface condensation of CO2 onto kaolinite. Environmental Science \& Technology Letters, 1(2), 142-145.

Schell, J., Casas, N., Pini, R., \& Mazzotti, M. (2012). Pure and binary adsorption of CO2, H2, and N2 on activated carbon. Adsorption, 18(1), 49-65.

Stern, N. (2009). The global deal: Climate change and the creation of a new era of progress and prosperity. PublicAffairs.

Stadie, Nicholas. "Synthesis and thermodynamic studies of physisorptive energy storage materials." PhD diss., California Institute of Technology, 2012.

Stadie, N. P., Murialdo, M., Ahn, C. C., \& Fultz, B. (2013). Anomalous isosteric enthalpy of adsorption of methane on zeolite-templated carbon. Journal of the American Chemical Society, 135(3), 990-993.

Stadie, N. P., Murialdo, M., Ahn, C. C., \& Fultz, B. (2015). Unusual Entropy of Adsorbed Methane on Zeolite-Templated Carbon. The Journal of Physical Chemistry C, 119(47), 26409-26421.

Singh, H., \& Javadpour, F. (2016). Langmuir slip-Langmuir sorption permeability model of shale. Fuel, 164, 28-37.

Tang, X., Ripepi, N., \& Gilliland, E. (2015). Isothermal adsorption kinetics properties of carbon dioxide in crushed coal. Greenhouse Gases: Science and Technology.

Tang, X. (2016). Comments on paper "Langmuir slip-Langmuir sorption permeability model of shale". Fuel, 181, 1095.

Tang, X., Ripepi, N., Stadie, N. Yu, L. \& Hall, M. (2016) A dual-site Langmuir equation for accurate estimation of high pressure deep shale gas resources. Fuel. DOI:10.1016/j.fuel.2016.07.088.

Toribio, M. M., Oshima, Y., \& Shimada, S. (2004). Evaluation of sequesterable carbon dioxide in Japanese coal samples at sub-critical and supercritical conditions. Studies in Surface Science and Catalysis, 153, 375-380.

The Paris Protocol - A blueprint for tackling global climate change beyond 2020 (2015): http://eurlex.europa.eu/legal-content/EN/TXT/?qid=1425546396765\&uri=COM:2015:81:FIN 
van Bergen, F., Pagnier, H., \& Krzystolik, P. (2006). Field experiment of enhanced coalbed methane-CO2 in the upper Silesian basin of Poland. Environmental Geosciences, 13(3), 201-224.

Wei, N., Li, X., Fang, Z., Bai, B., Li, Q., Liu, S., \& Jia, Y. (2015). Regional resource distribution of onshore carbon geological utilization in China. Journal of $\mathrm{CO} 2$ Utilization.

Weniger, P., Kalkreuth, W., Busch, A., \& Krooss, B. M. (2010). High-pressure methane and carbon dioxide sorption on coal and shale samples from the Paraná Basin, Brazil. International Journal of Coal Geology, 84(3), 190-205.

Wong, S., Law, D., Deng, X., Robinson, J., Kadatz, B., Gunter, W. D., ... \& Zhiqiang, F. (2007). Enhanced coalbed methane and CO 2 storage in anthracitic coals-micro-pilot test at South Qinshui, Shanxi, China. International Journal of Greenhouse Gas Control, 1(2), 215-222.

White, C. M., Strazisar, B. R., Granite, E. J., Hoffman, J. S., \& Pennline, H. W. (2003). Separation and capture of $\mathrm{CO} 2$ from large stationary sources and sequestration in geological formations -coalbeds and deep saline aquifers. Journal of the Air \& Waste Management Association, 53(6), 645-715.

White, C. M., Smith, D. H., Jones, K. L., Goodman, A. L., Jikich, S. A., LaCount, R. B., ... \& Schroeder, K. T. (2005). Sequestration of carbon dioxide in coal with enhanced coalbed methane recovery a review. Energy \& Fuels,19(3), 659-724.

Wu, T., \& Zhang, D. (2016). Impact of Adsorption on Gas Transport in Nanopores. Scientific Reports, 6.

Yamasaki, A. (2003). An overview of CO2 mitigation options for global warming-Emphasizing CO2 sequestration options. Journal of Chemical Engineering of Japan, 36(4), 361-375.

Yu, W., \& Sepehrnoori, K. (2014). Simulation of gas desorption and geomechanics effects for unconventional gas reservoirs. Fuel, 116, 455-464.

Zhou, L., Zhou, Y., Bai, S., Lü, C., \& Yang, B. (2001). Determination of the adsorbed phase volume and its application in isotherm modeling for the adsorption of supercritical nitrogen on activated carbon. Journal of colloid and interface science, 239(1), 33-38. 